This item was submitted to Loughborough's Research Repository by the author.

Items in Figshare are protected by copyright, with all rights reserved, unless otherwise indicated.

\title{
Improving water and sanitation provision globally through information sharing
}

PLEASE CITE THE PUBLISHED VERSION

PUBLISHER

(c) WEDC, Loughborough University

VERSION

VoR (Version of Record)

\section{PUBLISHER STATEMENT}

This work is made available according to the conditions of the Creative Commons Attribution-NonCommercialNoDerivatives 4.0 International (CC BY-NC-ND 4.0) licence. Full details of this licence are available at: https://creativecommons.org/licenses/by-nc-nd/4.0/

\section{LICENCE}

CC BY-NC-ND 4.0

\section{REPOSITORY RECORD}

Mulenga, Martin. 2019. "Improving Water and Sanitation Provision Globally Through Information Sharing". figshare. https://hdl.handle.net/2134/29394. 
33rd WEDC International Conference, Accra, Ghana, 2008

\author{
ACCESS TO SANITATION AND SAFE WATER: \\ GLOBAL PARTNERSHIPS AND LOCAL ACTIONS
}

\title{
Improving water and sanitation provision globally through information sharing
}

\author{
Martin Mulenga*, UK
}

\begin{abstract}
Despite huge investments in the water and sanitation sector over the years, millions of urban poor communities still remain unserved with adequate water supply and improved sanitation services. Part of the problem has been the failure to give attention to indicators, financial mechanisms and institutions that are designed by local organisations at local level. This paper, which describes an ongoing project, shows that there are many innovative and inspiring examples of locally driven initiatives that improve water and sanitation in low-income urban areas. The project aims to create an environment where local teams can learn directly from each other and provide a basis for better understanding of how to identify and build upon local initiatives that are likely to improve water and sanitation in low-income urban settlements. Although efforts to replicate such local successes have been disappointing, there have been important advances in local information collection, financing and organisation.
\end{abstract}

\section{Introduction}

The failure of approaches used in the past in the provision of water and sanitation to those living in low-income urban areas has left many people still lacking adequate water and improved sanitation. One of the major reasons for this situation has been due to the majority of governments and water and sanitation agencies in the Southern countries planning their services with limited or no participation of the urban poor.

Questions still remain, therefore, about how to ensure that the urban poor participate in water and sanitation programmes in practice, especially in view of weak democratic processes in many countries in the South (Mulenga, 2003). In most cases, the situation of poor urban communities is exacerbated by the fact that their settlements are considered illegal; for this reason they lack access to decision-making mechanisms. Where governments have attempted to assist the urban poor, their activities have been hampered by lack of accurate statistics for planning, and the lack of understanding of the needs, perceptions, and coping strategies of the urban poor. To meet the Millennium Development Goals (MDGs), the United Nations believes that coordinated action is required, not just from governments but also from people who use the water and sanitation facilities and those who invest in them.

\section{The international response}

The dominant response, however, has been to look to internationally comparable indicators to monitor progress, international financial mechanisms to fund improvements, and internationally endorsed institution shifts (e.g. more private sector participation) to drive improvements. Insufficient attention is being given to indicators, financial mechanisms and institutions that are designed by and for localities. There are many innovative and inspiring examples of locally driven initiatives that improve water and sanitation provision in deprived urban areas, including some that have reached considerable scale. Efforts to replicate local successes or models have been disappointing. But there have been important advances in local information collection, financing, and organisation.

\section{The project}

The International Institute for Environment and Development (IIED) based in London, and its partners in Angola (Development Workshop -DW), Argentina (IIED-America Latina), Ghana (People's Dialogue Ghana - PDG), Pakistan (Orangi Pilot Project Research and Training Institute - OPP-RTI) and India (The Society for the Promotion of Area Resources Centre - SPARC), are currently working on a Sida, Danida 
and DFID funded project entitled: Improving Water and Sanitation Provision Globally, Through Information and Action Driven Locally. The partners were identified because they are engaged in innovative efforts to improve conditions in urban poor communities, including local water and sanitation. The aim of this project is to enable the partners to learn and share experiences directly from each other, and influence the efforts of international agencies to improve water and sanitation in deprived urban communities. Although the teams may have different strategies, there are striking similarities and common principles. All the partners work outside the water sector, but have a deep understanding of the conditions and politics of urban poverty. Each team has designed their part of the project so that it contributes to the local agenda, but also so that they can all combine to have an important impact internationally. Building on these advances and sharing them among localities are critical to achieving international water and sanitation targets. Although most of the partners are already performing well it is hoped that through this project, the teams involved in the network will increase their capacity to address local water and sanitation deficiencies through what they have learned from other successful initiatives.

\section{Methodology}

The project evolved from an international workshop held in London in December 2004, which brought together a number of international water sanitation researchers and practitioners. At the workshop, it was concluded that there was need to develop a better understanding of how to identify and support successful locally driven initiatives to improve water and sanitation provision in urban poor communities. To allow for effective dialogue and sharing of information between the teams working on this project, a web based discussion forum has been set up. The discussion forum offers a platform through which any common themes, common approaches, sharing of experiences and resources can debated and the knowledge shared easily. The sharing of ideas also enables the teams to inspire each other. It is also planned that the experiences will be documented and disseminated more widely through various media.

In order to help focus the work, four key issues in the water and sanitation sector have been identified and agreed upon by the participating teams. These issues have made it easier for the teams to link the more group-specific issues with those of other teams at the international level. The issues are:

- Working in collaboration

- Loans, subsidies and financing water and sanitation improvements

- Using information to drive local action and monitor improvements

- Going to scale

The issues are discussed in more detail below.

\section{Working in collaboration}

Partnership has always been recognised as a key component in the achievement of development in communities. It must be noted that community-driven water and sanitation improvements are very limited if they are pursued by communities acting on their own. The same applies to private, market-driven improvement efforts, and to government-driven schemes, at least when it comes to improving conditions in the most deprived urban areas. Much depends on the relations between these communities, government authorities and water and sanitation providers, both formal and informal. A great number of development projects are designed and implemented by professionals which permit urban poor groups no influence and which rarely produce the hoped for improvements in water and sanitation. Many professionals object to community-driven projects because their own role and importance is diminished - and because their professional training did not equip them to know how to work with urban poor groups and to support their initiatives. And in most cases, the official development assistance agencies find it difficult to support community-driven development because their structures and procedures were never designed to do so.

However, new and interesting methods and institutional structures have emerged in urban poor communities, sometimes leading to unusual partnerships, the establishment of new institutions such as water boards or community-based organisations with legal standing, and the development of new "paperwork" (including contracts, charters, licences and regulations. The Orangi Pilot Project in Pakistan has become one of the best-known examples of $\mathrm{NGO}$ /community collaboration in developing infrastructure. It has demonstrated that low-income households can afford to pay the full cost of installing basic drainage and sewerage, if all households within a street or lane work collectively, generally collecting small contributions from each household and sub-contracting the work (Hasan, 1997).

In Angola, Development Workshop has supported the construction and management of 200 standpipes, and the development of local elected committees to manage these standpipes, working in collaboration with the water utility and the local authority. 
IIED-America Latina also offers another successful example of working collaboratively. In the past few years, the organisation has been working on a project that aims to build the capacity of local government and communities to allow them to work together in the framework of a partnership-based management model to provide water and sanitation services to informal settlements of Moreno, Buenos Aires. It is hoped that through this project the partnership-based management model will become institutionalised, so that each actor will demonstrate its commitment by allocating staff that understand and cater to the particular needs of service provision to the urban poor groups, and all actors will enter into formal agreement to coordinate service provision. In order for these initiatives to work, however, communities need to be organised and committed and the water and sanitation agencies need to be responsive to the needs of these people.

\section{Financing water and sanitation}

Financing and cost recovery are key issues for sustainable water and sanitation schemes. Considering the importance of household and community action and investment in improving water and sanitation, there is need to develop appropriate finance schemes. The impact of better local financial systems on improving the provision for water and sanitation may be direct - as they fund these improvements - or indirect as, for instance, they finance urban poor communities acquiring official tenure of their land, which then allows official water and sanitation utilities to serve them. In one sense, loan finance might seem inappropriate for low-income households, especially the poorest, since they have the least capacity to repay loans. But experience from the participating teams has shown that if loan packages are designed and managed in ways that match the needs and repayment capacities of low-income households, limited funding can go much further. In addition, when a small loan is combined with community-driven initiatives that strive to keep down unit costs, its potential becomes much greater. Collective loans can have particular importance - for instance by allowing savings groups formed by urban poor households to purchase land together and on which new housing can be developed. Subsidies too can play a role, at least when they are part of a viable financing strategy.

The different partners in this project have had different experiences, and have employed different approaches to address the financing challenges, potentially raising a wide range of questions. To what extent, or under what conditions/strategies, is it important for community groups themselves to gain the capacity to manage finance? What are the advantages and disadvantages of loan-based financing - for households, communities, utilities and countries? Are there ways of designing subsidies that ensure that they actually help improve water and sanitation provision in deprived areas?

In Orangi, for example, OPP-RTI provides communities with maps and plans, estimates of labour and materials, tools, training for carrying out the work but communities finance the work and manage the finances. By involving the communities in the financing and construction of sewers, the costs have been far cheaper than if the government agencies had built them. The Orangi experience also shows that the extension of services to the urban poor need not be about securing external finance, but can be achieved through the development of competent, capable, accountable local agencies or utilities that can work with community organisations.

\section{Using information to drive local action and monitor improvements}

One of the major reasons given by government agencies for their failure to extend services to slums and squatter settlements has been the lack of baseline data about these settlements. All of the partners on this project have used locally gathered or processed information to help drive local action. Some involves using high-tech equipment, much of it is map-based, and almost all of it serves a clear strategic purpose.

To initiate action and dialogue with government agencies, the partners on this project carry out detailed slum enumerations and surveys that draw information from each household and develop detailed maps with the participation of the residents. The maps provide a basis for detailed plans for development. All the teams have found mapping to be a very useful tool to gather information about existing conditions in areas where they work. Through mapping communities have been more knowledgeable about their situation, and empowered to challenge and find solutions to the issues they face. OPP-RTI, for example, has successfully prepared maps for all informal settlements in Karachi, Pakistan and these now provide a city-wide picture that allows planning for city-wide systems, as well as providing the basis for community-managed investments in each settlement. OPP-RTI has also prepared handbooks for local councillors to show them what is needed to improve services in their constituencies.

The improvement of data collection at community level could also complement a new initiative that pro- 
motes benchmarking of urban water and sanitation facilities. Benchmarking involves identifying industry best practices, measuring and comparing one's own performance against others, identifying key areas for improvement and upgrading to match the best (WSP, 2007). In India for instance, it is reported that the Ministry of Urban Development is committed to institutionalising benchmarking because of its potential to improve urban services.

\section{Going to scale}

A common criticism of community-driven water and sanitation programmes, is that they cannot deliver at scale. The international development community is therefore currently promoting scaling up of successful water and sanitation projects especially those initiated by local communities. It is hoped that by doing so more people will have an opportunity of gaining access to water and sanitation facilities in the near future. It is also believed that this is an effective way of fulfilling the MDG targets on water and sanitation by 2015 .

This project has shown so far that there are many local organisations that have been able to run successful initiatives. In many low-income urban settlements, local groups have been able to collaborate to improve water and sanitation services, often under very trying circumstances. What is needed therefore is for the authorities and donors to find ways of supporting such initiatives. Some successful initiatives may be difficult to scale up because of the varying local conditions and the policy environment. Findings from some of the project participants show that most community driven water and sanitation programmes have been easier to scale up because city authorities have supported them. At least that has been the experience of SPARC, OPP-RTI and IIED-AL. Another key finding has been the need to involve the residents of the urban poor settlements in the development of a city-wide information base which shows the conditions in various settlements. This enables the residents to identify the communities, which need interventions most urgently, and helps develop linkages between all the urban poor communities. The development of pilot projects planned within the city-wide consultations involving urban poor groups that serve as precedents have also been able to encourage other urban poor groups to take action elsewhere. Experience also shows that involving people in this manner also stimulates the political changes that allow an upgrading scheme to evolve into a larger process in which all the urban poor communities are involved.

\section{Conclusions}

Although this project is ongoing there are a number of conclusions that can be made. In the five case studies, there have been many local innovations in gathering and using information to drive water and sanitation improvement -for instance through partnerships between urban poor organisations, local NGOs and municipal governments that map deficiencies in provision. There are also local innovations in addressing the challenge of financing improvements in low-income settlements, and developing institutions that respond to local water and sanitation deficiencies. Many of these local innovations not only improve water and sanitation provision, but do so in a way that involves and responds to communities far more than conventional water and sanitation projects do.

\section{Further reading}

Hasan, A. (1997) Working with Government: The Story of the Orangi Pilot Project's Collaboration with State Agencies for Replicating its Low Cost Sanitation Programme. Karachi, City Press.

Mulenga, M. (2004) Building Links for improved sanitation in poor urban settlements: Recommendations from research in Southern Africa. University of Southampton.

Satterthwaite, D., G. McGranahan and D. Mitlin (2005) Community-driven development for water and sanitation in urban areas - Its contribution to meeting the Millennium Development Goal Targets. WSSCC, Geneva.

WSP (2007) 'Benchmarking of Urban water and Sanitation Facilities gains Momentum in India' article. WSP website: http://www.wsp.org/news/featured.asp?id=81.

\section{Note/s}

*With contributions from Development Workshop (Angola), IIED-AL (Argentina), Orangi Pilot Project Research and Training Institute (Pakistan), People's Dialogue (Ghana) and SPARC (India) 


\section{Keywords}

working collaboratively, urban poor, water and sanitation, going to scale, community participation

\section{Contact details}

Martin Mulenga

International Institute for

Environment and Development (IIED),

3 Endsleigh Street, London, WC1H 0DD

Tel: +44 (0) 2073882117

Fax: +44 (0) 2073882826

Email: Martin.Mulenga@iied.org

www: www.iied.org 